\title{
PENGEMBANGAN LEMBAR KERJA SISWA MELALUI MODEL BLENDED LEARNING BERBASIS BUDAYA MELAYU SAMBAS MATERI ARITMATIKA SOSIAL KELAS VII SMP
}

\author{
Jasmin Loise Tasa \\ Universitas Katolik Santo Thomas, Medan; \\ jasminloise@gmail.com
}

\begin{abstract}
Abstrak. Penelitian ini bertujuan untuk 1) mengetahui validitas dari Lembar Kerja Siswa (LKS) melalui model Blended Learning berbasis budaya Melayu Sambas, 2) mengetahui efektifitas dari Lembar Kerja Siswa (LKS) melalui model Blended Learning berbasis budaya Melayu Sambas sehingga dapat digunakan untuk mempelajari materi Aritmatika Sosial di kelas VII SMP. Penelitian ini menggunakan metode penelitian dan pengembangan atau research and development $(R \mathcal{E} D)$ model pengembangan ADDIE dengan tahapan (1) Analysis (Analisis), (2) Design (Perancangan), (3) Develop (Pengembangan), (4) Implement (Implementasi), (5) Evaluation (Evaluasi). Berdasarkan analisis data dan pembahasan, diperoleh data hasil validasi ahli materi dengan rata-rata total penilaian sebesar 4,2 berada pada kategori baik sehingga Lembar Kerja Siswa (LKS) dikatakan valid. Dari hasil penelitian diperoleh bahwa keefektifan Lembar Kerja Siswa (LKS) melalui model Blended Learning berbasis budaya Melayu Sambas diperoleh beberapa penilaian melalui tes hasil belajar sebagai berikut: 1) Ketuntasan belajar siswa secara klasikal sebesar 85,18\% berada pada kategori tuntas; 2) Ketercapaian indikator kompetensi dengan persentase sebesar $83,52 \%$ berada pada kategori tuntas; 3 ) Hasil observasi kemampuan guru mengelola pembelajaran dengan nilai rata-rata sebesar 3,75 berada pada kategori sangat baik; 4) Waktu pembelajaran yang efektif selama 4 kali pertemuan; 5) Angket respon siswa terhadap LKS dengan rata-rata penilaian sebesar 4,52 berada pada kategori positif. Berdasarkan analisis data di atas, dapat disimpulkan bahwa Lembar Kerja Siswa (LKS) yang dikembangkan melalui model Blended Learning berbasis budaya Melayu Sambas
\end{abstract}

Cartesius: Jurnal Pendidikan Matematika Vol. 2, No. 2

CProdi Pendidikan Matematika Universitas Katolik Santo Thomas 
materi Aritmatika Sosial kelas VII SMP adalah valid dan efektif untuk digunakan dalam menunjang pembelajaran matematika.

Kata kunci. LKS, blended learning, budaya Melayu Sambas.

Abstract. This study aims to 1) find out the validity of Student Worksheets (LKS) through the Blended Learning model based on Sambas Malay culture, 2) find out the effectiveness of Student Worksheets (LKS) through the Blended Learning model based on Sambas Malay culture so that it can be used to study Arithmetic material Social in class VII of junior high school. This study uses the research and development method or research and development ( $R \in \mathcal{E} D$ ) development model of ADDIE with stages (1) Analysis (Analysis), (2) Design (Design), (3) Develop (Development), (4) Implement (Implementation), (5) Evaluation. Based on data analysis and discussion, data obtained from material expert validation were obtained with an average total rating of 4.2 in the good category so that the Student Worksheet (LKS) was said to be valid. From the results of the study, it was found that the effectiveness of Student Worksheets (LKS) through the Blended Learning model based on Sambas Malay culture obtained several judgments through the learning outcomes test as follows: 1) Student learning completeness in a classical manner was $85.18 \%$ in the complete category; 2) Achievement of competency indicators with a percentage of $83.52 \%$ in the complete category; 3 ) The results of the observation of the teacher's ability to manage learning with an average value of 3.75 are in the excellent category; 4) Effective learning time for 4 meetings; 5) Questionnaire of student responses to LKS with an average rating of 4.52 in the positive category. Based on the analysis of the above data, it can be concluded that Student Worksheets (LKS) developed through the Blended Learning model based on Sambas Malay culture of Social Sciences Arithmetic class VII SMP are valid and effective to be used to support mathematics learning.

Keywords. LKS, blended learning, Sambas Malay culture.

\section{PENDAHULUAN}

Matematika merupakan satu diantara banyaknya mata pelajaran yang secara umum dianggap cukup sulit bagi siswa. Secara umum

Cartesius: Jurnal Pendidikan Matematika Vol. 2, No. 2

CProdi Pendidikan Matematika Universitas Katolik Santo Thomas 
siswa beranggapan bahwa pelajaran matematika hanya terpusat pada hitungan, berisi banyak angka, kurang menarik dan banyak rumus yang membingungkan. Pada sebagian besar sekolah, metode konvensional masih diterapkan oleh guru di dalam proses pembelajaran matematika. Metode konvensional ini dilakukan dengan sistem teacher centered. Pada pembelajaran matematika, guru sering mengalami kekurangan alokasi waktu belajar. Jumlah alokasi waktu belajar yang ditetapkan tidak sesuai dengan tuntutan tujuan pembelajaran yang harus dicapai. Kekurangan alokasi waktu menyebabkan guru menggunakan sistem "kejar tayang" untuk menyampaikan materi di bagian akhir. Hal inilah yang menjadikan pembelajaran matematika di kelas kurang optimal. Sehingga kualitas belajar pun juga kurang optimal. Dengan adanya kemajuan teknologi dapat mengubah metode pembelajaran yang dulunya dilakukan secara konvensional menjadi metode pembelajaran yang modern berbasis internet. Pemanfaatan teknologi informasi dan komunikasi dalam proses pembelajaran modern mampu menjadi media sekaligus sumber pembelajaran yang bisa dipilih oleh guru untuk dipakai dalam proses belajar mengajar. Perkembangan TIK juga dapat membuat guru semakin kreatif dalam menuangkan ide misalnya dengan animasi atau simulasi yang bisa digunakan untuk mendukung proses pembelajaran dengan cakupan yang luas. Dengan adanya proses pembelajaran tersebut, siswa dapat belajar secara mandiri. Selain itu, dengan adanya kemajuan teknologi informasi dan komunikasi menciptakan konsep baru dalam pembelajaran yang berbasis internet atau yang dikenal dengan istilah $E$ Learning. Kehadiran e-learning ini menghadirkan model pembelajaran yang terbaru seperti blended learning, mobile learning, web-based learning, virtual learning, internet learning, networked learning dan distance learning. Dengan banyaknya model pembelajaran ini, maka proses pembelajaran matematika dapat disajikan menjadi lebih menarik dan lebih efektif sehingga dapat memenuhi tujuan pembelajaran. Dengan memanfaatkan model pembelajaran blended learning, guru yang berperan sebagai fasilitator mampu memberikan "warna" dalam pembelajaran matematika. Model blended learning merupakan kombinasi antara keunggulan pembelajaran tatap muka dan pembelajaran virtual. Blended learning juga

Cartesius: Jurnal Pendidikan Matematika Vol. 2, No. 2

CProdi Pendidikan Matematika Universitas Katolik Santo Thomas 
berarti penggunaan sebuah metode yang bervariasi yang mana mengkombinasikan pertemuan tatap muka langsung di kelas dan pembelajaran secara online untuk memperoleh objektivitas pembelajaran. Ada banyak strategi yang dapat digunakan untuk mengembangkan Blended Learning yang dibutuhkan oleh guru dan siswa. Pembelajaran online akan jauh lebih menarik bila dilengkapi dengan media e-learning seperti edmodo. Aplikasi Edmodo merupakan suatu platform microblogging yang bersifat pribadi dimana aplikasi ini dikembangkan bagi guru dan siswa, tetapi privasi siswa tetap diutamakan. Pada aplikasi ini, guru dan siswa bisa saling berbagi catatan, tautan, dan dokumen yang berhubungan dengan materi pelajaran, khususnya matematika. Guru juga bisa memberi sebuah peringatan terkait dengan tugas untuk siswa sesuai dengan kerangka waktu yang diputuskan yang bisa dilihat oleh semua anggota yang bergabung. Selaras dengan pernyataan tersebut, Basori (2013: 1) menjelaskan "Edmodo adalah suatu aplikasi pembelajaran online yang sangat menarik dan sesuai untuk guru dan siswa dengan tampilan yang menyerupai aplikasi facebook, tetapi perbedaannya yaitu Edmodo lebih berguna sebagai sarana untuk edukasi berbasis jejaring sosial.

Di era digital sekarang ini khususnya perkotaan, proses pembelajaran yang ada di sekolah tidak terlepas dari teknologi. Tidak dapat dihindari lagi bahwa penggunaan teknologi dapat menciptakan pembelajaran yang lebih menarik dan tidak membosankan serta dapat meningkatkan mutu atau kualitas belajar mengajar. Guru yang memiliki peran sebagai fasilitator juga dituntut untuk dapat menguasai dan menerapkan media berbasis teknologi. Hal ini disebabkan karena penggunaan media pembelajaran dapat memberikan stimulus bagi siswa sehingga pemahaman siswa dapat ditingkatkan terhadap suatu materi serta hasil belajar dapat dicapai secara optimal. Namun fakta yang diperoleh oleh peneliti di lapangan pada saat melaksanakan observasi penelitian di sekolah SMP Swasta GKPI Padang Bulan Medan adalah pada proses pembelajaran matematika, guru masih melakukan proses belajar mengajar secara konvensional yang biasanya diawali dengan menyajikan materi pembelajaran melalui metode ceramah, memberikan soal dan meminta

Cartesius: Jurnal Pendidikan Matematika Vol. 2, No. 2

CProdi Pendidikan Matematika Universitas Katolik Santo Thomas 
siswa mengerjakan kemudian dibahas bersama. Metode ini sering membuat siswa merasa cepat jenuh dan bosan serta tidak mendapatkan ilmu yang cukup banyak karena sumber ilmu hanya diperoleh dari guru dan buku panduan belajar saja. Fakta lain yang juga diperoleh adalah guru juga belum memanfaatkan fasilitas internet yang disediakan sekolah secara maksimal guna menunjang proses pembelajaran. Hal itu dikarenakan keterampilan guru yang kurang dalam memanfaatkan fasilitas social networking sehingga guru kurang update mengenai aplikasi belajar yang baru seperti edmodo. Padahal aplikasi edmodo ini dapat digunakan untuk mendorong tercapainya tujuan pembelajaran dan membuat alokasi waktu lebih efisien. Sehingga dapat mengatasi masalah kekurangan alokasi waktu yang selama ini sering dialami guru pada proses pembelajaran matematika. Pada sekolah SMP Swasta GKPI Padang Bulan Medan kekurangan alokasi waktu disebabkan karena banyaknya pelaksanaan berbagai jadwal kegiatan di sekolah tersebut. Peneliti juga menemukan masih banyaknya bahan ajar yang digunakan guru khususnya Lembar Kerja Siswa (LKS) yang dibuat oleh orang lain ataupun buatan pabrik untuk kegiatan pembelajaran. Padahal bahan ajar tersebut kurang sesuai dengan lingkungan dan situasi sosial budaya siswa. LKS yang digunakan pun kebanyakan kurang menarik dan hanya berisi rangkuman materi dan kumpulan soal-soal. LKS yang digunakan juga hanya menjadi bahan pembelajaran saat jam kosong atau untuk pekerjaan rumah. Selain itu, umumnya LKS yang digunakan hanya bersifat kognitif sedangkan untuk aspek sikap dan keterampilan belum terlalu terlihat. Hal inilah yang menjadi alasan kenapa siswa merasa cepat bosan dan tidak tertarik dalam pembelajaran matematika sehingga siswa mengalami kesulitan dalam pembelajaran matematika. Menurut Kereh, Subandar, \& Tjiang (2013: 11) menyatakan bahwa “Istilah kesulitan belajar dalam konten matematika dapat diartikan sebagai kesulitan siswa yang dapat diungkapkan dari pola kesalahan jawaban yang dibuat oleh siswa dalam mengerjakan soal". Ada beberapa kesalahan yang dibuat oleh siswa yaitu berupa kesalahan pola pikir awal, pemikiran tidak terarah, pemikiran individual, tidak lengkapnya penalaran atau salah, intuisi yang tidak benar, kemampuan dan minat belajar (Suparno, 2013: 34). Selain itu

Cartesius: Jurnal Pendidikan Matematika Vol. 2, No. 2

(CProdi Pendidikan Matematika Universitas Katolik Santo Thomas 
Savitri (2016: 403) menyimpulkan bahwa "Kebanyakan siswa hanya memahami konsepnya, sehingga ketika dihadapkan pada persoalan yang baru, mereka mengalami kebingungan yang berujung terjadinya kesalahan". Untuk mengatasi kesulitan-kesulitan yang didapat oleh siswa selama proses pelajaran matematika, maka dikembangkanlah media pembelajaran berbasis teknologi untuk menunjang tercapainya keberhasilan pembelajaran matematika. LKS adalah suatu media pembelajaran yang sangat mendukung.

Menurut Damayanti (2013: 58), “LKS merupakan satu diantara banyaknya media ajar yang menunjang tercapainya keberhasilan pembelajaran matematika". Dengan mengembangkan LKS yang terintegrasi teknologi salah satunya dengan menggunakan model blended learning dapat mendukung pembelajaran. Model ini dapat meningkatkan keterampilan siswa dengan tuntutan zaman yang semakin pesat (Wijayanti, 2017). Salah satu materi yang dipelajari di SMP kelas VII adalah aritmatika sosial. Materi Aritmatika Sosial dipilih sebagai materi dalam pengembangan LKS dikarenakan sangat erat kaitannya di kehidupan nyata siswa. Pengembangan LKS yang terintegrasi dengan teknologi juga tidak terlepas dari nilai-nilai budaya daerah. Pada masa ini, nilai-nilai budaya daerah sudah mulai bergeser seiring dengan perkembangan teknologi yang semakin pesat. Banyaknya informasi dan budaya luar yang masuk dapat membuat siswa lupa dan mulai menghilangkan nilai budaya mereka. Padahal, budaya daerah merupakan jati diri dan identitas bangsa yang perlu dilestarikan, dijaga dan dimanfaatkan oleh generasi penerus bangsa. Nilai luhur budaya bangsa merupakan warisan budaya yang sangat tepat jika digunakan sebagai dasar pembinaan sumber daya manusia (Effendi dalam Nani Tuloni dkk, 2003: 18). Pengembangan LKS berbasis budaya telah dikembangkan dalam penelitian oleh Dameria.S dkk (2018: 81) untuk melihat respon siswa terhadap pembelajaran matematika realistik berbasis konteks budaya Batak Toba dalam pembelajaran. Hasil penelitian yang diperoleh adalah respon positif yang diperoleh dari siswa terkait pembelajaran matematika realistik menggunakan konteks budaya Batak Toba. Dengan kata lain, siswa

Cartesius: Jurnal Pendidikan Matematika Vol. 2, No. 2

CProdi Pendidikan Matematika Universitas Katolik Santo Thomas 
senang terhadap komponen pembelajaran yang digunakan, komponen pembelajaran yang digunakan adalah baru, siswa berminat untuk melaksanakan pembelajaran yang sama pada pembelajaran selanjutnya dan siswa tertarik dengan komponen belajar yang digunakan. Berdasarkan uraian di atas, maka perlu dilakukan penelitian dengan judul “Pengembangan Lembar Kerja Siswa Melalui Model Blended Learning Berbasis Budaya Melayu Sambas Materi Aritmatika Sosial Kelas VII SMP Swasta GKPI Padang Bulan Medan Tahun Ajaran 2018/2019". Dengan harapan akan diterapkan dalam proses pembelajaran dan menunjang tercapainya keberhasilan pembelajaran matematika sekaligus memperkenalkan dan melestarikan nilai-nilai budaya Indonesia.

\section{METODE}

Pendekatan penelitian yang dilakukan oleh peneliti yaitu pendekatan campuran kuantitatif dan kualitatif. Metode penelitian yang dilakukan adalah metode penelitian dan pengembangan atau Research and Development (R\&D). Penelitian ini dilaksanakan di SMP Swasta GKPI Padang Bulan Medan pada semester genap tahun pembelajaran 2018/2019. Populasi penelitian ini adalah siswa SMP Swasta GKPI Padang Bulan Medan kelas VII-I Tahun Ajaran 2018/2019 terdiri dari 27 orang siswa. Model pengembangan yang diterapkan adalah model pengembangan ADDIE. Secara visual tahapan model ADDIE dapat dilihat pada bagan berikut:

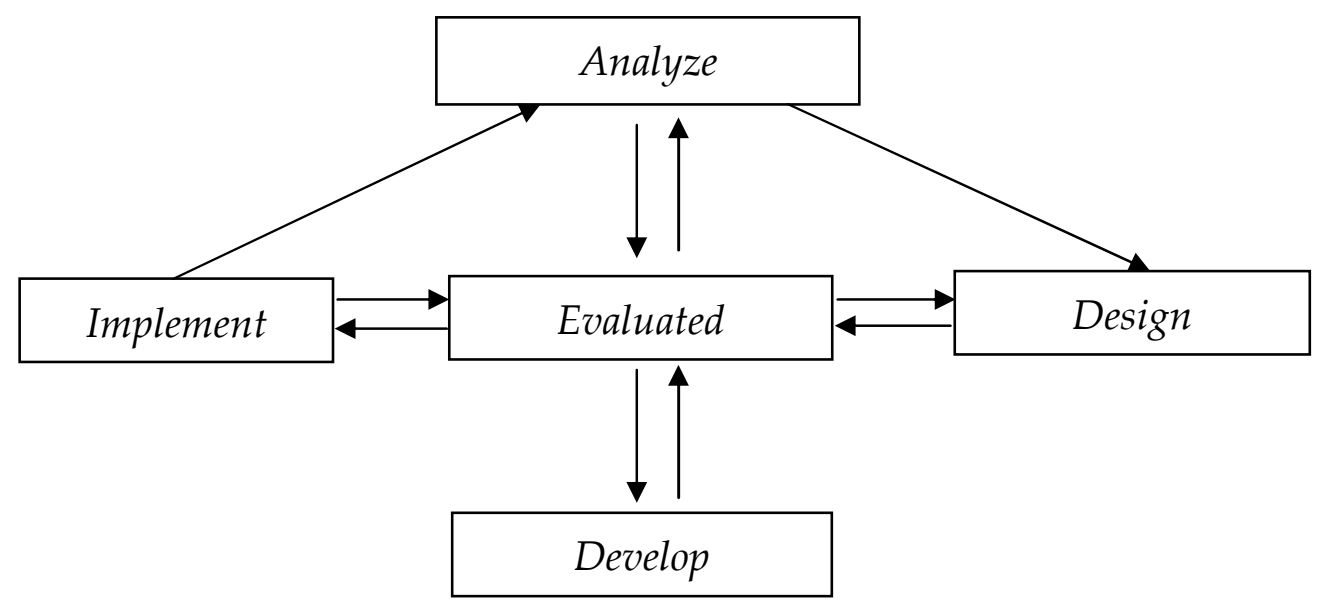

Gambar 1. Tahap Pengembangan Produk Model ADDIE

Cartesius: Jurnal Pendidikan Matematika Vol. 2, No. 2

CProdi Pendidikan Matematika Universitas Katolik Santo Thomas 
Penelitian ini menggunakan dua jenis data yaitu data kuantitatif dan kualitatif. Data kuantitatif berupa nilai hasil belajar siswa. Data kualitatif berupa hasil penilaian ahli dan hasil lembar observasi kemampuan mengelola pembelajaran serta angket respon siswa. Sumber data penelitian diperoleh dari angket dan tes hasil belajar siswa. Teknik pengambilan sampel dalam penelitian ini dilakukan dengan teknik stratifikasi. Teknik ini dipilih peneliti karena kondisi populasi di sekolah SMP GKPI Padang Bulan Medan terdiri dari beberapa karakteristik yakni kebudayaan serta adat-istiadat yang berbeda. Teknik yang digunakan dalam penelitian ini adalah tes dan non-tes. Tes yang dimaksud yaitu tes hasil belajar. Selanjutnya, non-tes yang dimaksud pada penelitian ini adalah berupa lembar observasi kemampuan mengelola kelas serta angket respon siswa. Alat yang digunakan dalam penelitian ini adalah lembar validasi (RPP, LKS dan tes hasil belajar), data hasil belajar siswa, lembar kemampuan pengelolaan kelas dan angket respon siswa.

\section{Analisis Data Hasil Validasi Ahli}

Kevalidan perangkat pembelajaran diperoleh dari hasil analisis data lembar penilaian perangkat pembelajaran oleh validator. Analisis kevalidan dilakukan sebagai berikut:

a. Tabulasi data skor hasil penilaian perangkat pembelajaran dengan mengelompokkan butir-butir pertanyaan yang sesuai dengan aspekaspek yang diamati.

Tabel 1. Pedoman Penskoran terhadap Hasil Penilaian

\begin{tabular}{cc}
\hline Kriteria & Skor \\
\hline Sangat Baik & 5 \\
Baik & 4 \\
Cukup & 3 \\
Kurang & 2 \\
Sangat Kurang & 1 \\
\hline
\end{tabular}

b. Menghitung rata-rata skor tiap aspek dengan menggunakan rumus:

$$
\bar{x}=\frac{\sum_{i-1}^{n} x i}{n}
$$

Cartesius: Jurnal Pendidikan Matematika Vol. 2, No. 2

CProdi Pendidikan Matematika Universitas Katolik Santo Thomas 
Keterangan:

$\bar{x}=$ Rerata skor

$x_{i}=$ Skor keterangan ke-i

$\mathrm{n}$ = Banyaknya butir pertanyaan tiap aspek

Skor maksimal ideal adalah 5 dan skor minimal ideal adalah 1, maka diperoleh klasifikasi penilaian perangkat pembelajaran ditunjukkan pada tabel 2 berikut:

Tabel 2. Pedoman Kriteria Kevalidan

\begin{tabular}{cc}
\hline Interval Skor & Kriteria \\
\hline $\bar{x}>4,2$ & Sangat Baik \\
$3,4<\bar{x} \leq 4,2$ & Baik \\
$2,6<\bar{x} \leq 3,4$ & Cukup \\
$1,8<\bar{x} \leq 2,6$ & Kurang \\
$\bar{x} \leq 1,8$ & Sangat Kurang \\
\hline
\end{tabular}

Berdasarkan tabel 2 akan diperoleh kualifikasi kevalidan perangkat pembelajaran yang dikembangkan. Perangkat pembelajaran dikatakan valid bila minimal kualifikasi tingkat kevalidan yang diperoleh adalah baik.

\section{Analisis Keefektifan LKS}

\section{a. Ketuntasan Belajar Klasikal Siswa}

Untuk menghitung ketuntasan belajar klasikal dapat digunakan rumus:

$$
P K K=\frac{T}{T_{i}} \times 100 \%
$$

Keterangan:

PKK : Ketuntasan Klasikal

$\mathrm{T}$ : Jumlah siswa yang tuntas

$T_{t} \quad$ : Jumlah siswa total

\section{b. Ketercapaian Indikator}

Untuk menghitung pencapaian indikator dalam pembelajaran digunakan rumus:

Cartesius: Jurnal Pendidikan Matematika Vol. 2, No. 2

CProdi Pendidikan Matematika Universitas Katolik Santo Thomas 


$$
T=\frac{s_{i}}{s_{\text {maks }}} \times 100 \%
$$

Keterangan:

$\mathrm{T} \quad$ : Persentase pencapaian indikator

$s_{i} \quad$ : Jumlah skor siswa untuk butir soal ke-i

$S_{\text {maks }}:$ Jumlah skor maksimal untuk butir soal ke-i

Dengan kriteria:

$0 \% \leq \mathrm{T}<75 \%$ : Tujuan Pembelajaran Khusus (TPK) belum tercapai $75 \% \leq \mathrm{T}<100 \%$ : Tujuan Pembelajaran Khusus (TPK) tercapai

\section{c. Kemamampuan Mengelola Pembelajaran}

Kemampuan dalam mengelola pembelajaran dengan mencari rata-rata nilai kemampuan guru mengelola pembelajaran dari empat kali pembelajaran dan efektif bila mencapai kategori cukup baik. Kriteria tingkat kemampuan guru (TKG) mengelola pembelajaran (Hasratuddin, 2002: 48) adalah:

$$
\begin{aligned}
& 1,00 \leq 1,49 \text { adalah tidak baik } \\
& 1,50 \leq 2,49 \text { adalah kurang baik } \\
& 2,50 \leq 3,49 \text { adalah cukup baik } \\
& 3,50 \leq 4,00 \text { adalah sangat baik }
\end{aligned}
$$

\section{d. Waktu Pembelajaran}

Waktu pembelajaran selama uji coba yaitu tidak lebih atau sama dengan waktu pembelajaran biasa.

\section{e. Angket Respon Siswa}

Analisis angket respon siswa dapat dilakukan dengan cara berikut:

1) Tabulasi data skor hasil angket respon siswa dengan mengelompokkan butir-butir pernyataan sesuai dengan aspek-aspek yang diamati. Tabel 3 merupakan pedoman penskoran angket respon siswa menggunakan skala likert 1-5.

Cartesius: Jurnal Pendidikan Matematika Vol. 2, No. 2

(CProdi Pendidikan Matematika Universitas Katolik Santo Thomas 
Tabel 3 Pedoman Penskoran Angket Respon Siswa

\begin{tabular}{lcc}
\hline \multirow{2}{*}{ Kategori } & \multicolumn{2}{c}{ Skor Pernyataan } \\
\cline { 2 - 3 } & Positif & Negatif \\
\hline Sangat Setuju (SS) & 5 & 1 \\
Setuju (S) & 4 & 2 \\
Netral (N) & 3 & 3 \\
Tidak Setuju (TS) & 2 & 4 \\
Sangat Tidak Setuju (STS) & 1 & 5 \\
\hline
\end{tabular}

2) Menghitung rata-rata skor tiap aspek dengan menggunakan rumus:

$$
\bar{x}=\frac{\sum_{i=1}^{n} x i}{n}
$$

Keterangan:

$\bar{x} \quad:$ Rerata skor

$x i$ : Skor keterangan ke-i

$\mathrm{n} \quad$ : Banyaknya butir pernyataan tiap aspek

\section{HASIL DAN PEMBAHASAN}

Data-data hasil analisis penelitian menunjukkan bahwa ketuntasan belajar secara klasikal mencapai 85,18\%, persentase ketercapaian indikator sebesar $83,52 \%$, nilai rata-rata kemampuan guru mengelola pembelajaran sebesar 3,75 dengan kategori Sangat Baik, waktu pembelajaran efektif serta rata-rata penilaian angket respon siswa yang positif sebesar 4,52. Oleh karena itu, LKS matematika melalui model Blended Learning berbasis budaya Melayu Sambas pada materi aritmatika sosial di kelas VII yang telah dikembangkan dapat dikatakan valid dan efektif.

\section{KESIMPULAN}

Berdasarkan analisis data hasil penelitian dan pembahasan, maka dapat disimpulkan bahwa:

1. Lembar Kerja Siswa (LKS) yang dikembangkan melalui model Blended Learning berbasis budaya Melayu Sambas pada materi Aritmatika Sosial di kelas VII SMP adalah valid. Kevalidan LKS ditinjau dari penilaian oleh ahli Matematika berdasarkan komponen-komponen dalam LKS

Cartesius: Jurnal Pendidikan Matematika Vol. 2, No. 2

CProdi Pendidikan Matematika Universitas Katolik Santo Thomas 
dengan rata-rata total penilaian 4,2. Rata-rata total hasil validasi LKS adalah "Baik".

2. Lembar Kerja Siswa (LKS) yang dikembangkan melalui model Blended Learning berbasis budaya Melayu Sambas pada materi Aritmatika Sosial di kelas VII SMP adalah efektif. Keefektifan LKS ditinjau dari (1) Ketuntasan belajar siswa secara klasikal sebesar 85,18\%, Ketercapaian indikator dengan persentase pencapaian sebesar 83,52\%, (3) Kemampuan guru mengelola pembelajaran dengan nilai rata-rata keseluruhan kategori adalah 3,75, (4) Waktu pembelajaran yang digunakan pada saat uji coba adalah 4 kali pertemuan efektif selama $8 \mathrm{x}$ 40 menit serta (5) Angket respon siswa yang positif untuk setiap aspek terhadap LKS dengan rata-rata penilaian sebesar 4,52 dan masuk ke dalam kategori positif.

\section{UCAPAN TERIMAKASIH}

Penulis menyampaikan terima kasih kepada Ibu Shinta Dameria Simanjuntak, S.Si., M.Pd. sebagai Dosen Pembimbing 1 dan Ibu Tetty N. Sipayung, S.Si., M.Pd. sebagai Dosen Pembimbing 2 yang telah mengarahkan dan membimbing penulis mulai dari awal penelitian hingga berakhirnya penelitian sehingga penulis dapat menuliskan artikel ini yang merupakan bagian dari hasil penelitian penulis. Penulis juga menyampaikan terima kasih kepada Kepala Program Studi Pendidikan Matematika, Dekan, dan Rektor Universitas Katolik Santo Thomas Medan atas dukungan yang diberikan kepada penulis.

\section{DAFTAR PUSTAKA}

[1] Arikunto Suharsimi, 2010. Manajemen Penelitian. Edisi Revisi 2010. Jakarta: Rineka Cipta.

[2] Arikunto Suharsimi, 2013. Dasar-Dasar Evaluasi Pendidikan. Edisi Kedua 2013. Jakarta: Bumi Aksara.

[3] Aspia, Daulay, 2013. Media Pembelajaran. Medan: Perdana Publishing.

[4] Dwiyogo.W, 2018. Pembelajaran Berbasis Blended Learning. Edisi Pertama 2018. Depok: Rajawali Pers.

Cartesius: Jurnal Pendidikan Matematika Vol. 2, No. 2

CProdi Pendidikan Matematika Universitas Katolik Santo Thomas 
[5] Eggen. P, Kauchak.D, 2012. Strategi dan Model Pembelajaran. Edisi Keenam 2012. Jakarta: PT Indeks.

[6] Emzir, 2008. Metodologi Penelitian Pendidikan: Kuantitatif dan Kualitatif. Jakarta: Rajawali Pers.

[7] Galang Akbar, Suryaningtiyas. W, 2016. Penggunaan Model Pembelajaran Blended Learning Terhadap Hasil Belajar Matematika Kelas VIII di SMPN 38 Surabaya. Journal of Mathematics Education, Science and Technology: Volume 01 Nomor 01.

[8] Hadi R.F, Rulviana. V, 2018. Analisis Proses Pembelajaran E-Learning Berbasis Edmodo pada Mata Kuliah Geometri. Jurnal Bidang Pendidikan Dasar (JBPD): Volume 02 Nomor 01.

[9] Hasbullah, 2014. Blended Learning Trend Strategi Pembelajaran Matematika Masa Depan. Jurnal Formatif: Volume 04 Nomor 01.

[10]Jannah M.R, 2016. Penerapan Social Learning Network (Edmodo) pada Mata Kuliah Konstruksi Bangunan Gedung Bertingkat Rendah S1 Pendidikan Teknik Bangunan di Universitas Negeri Surabaya.

[11] Maran, Raga Rafael, 2000. Manusia E Kebudayaan dalam Perspektif Ilmu Budaya Dasar. Jakarta: PT Rineka.

[12] Murniati R.D, Sanjaya.M.G, 2013. Pengembangan Perangkat Pembelajaran Kimia Berbasis Blended Learning di SMA Negeri 7 Kediri. Unesa Journal of Chemical Education: Volume 02 Nomor 03.

[13]Nuraini Syifa, 2018. Pengembangan Lembar Kerja Siswa (LKS) Model Blended Learning Berorientasi Higher Order Thinking Skills pada Materi Hukum Newton Tentang Gerak. Bandar Lampung.

[14]Rahmana Y.A, 2015. Validitas Perangkat Pembelajaran Blended Learning Terintegrasi Edmodo pada Submateri Katabolisme Karbohidrat. Jurnal Unesa: Volume 04 Nomor 02.

[15]Riasari Diana, 2018. Peranan Model Pembelajaran Matematika Berbasis Blended Learning Terhadap Komunikasi Matematis Siswa dalam Materi Statistik pada SMAN 1 Tapung. Jurnal Pendidikan Tambusai: Volume 02 Nomor 04.

[16]Sanjaya. W, 2008. Perencanaan dan Desain Sistem Pembelajaran. Edisi Pertama 2008. Bandung: Kencana Prenamedia Group.

Cartesius: Jurnal Pendidikan Matematika Vol. 2, No. 2

CProdi Pendidikan Matematika Universitas Katolik Santo Thomas 
[17]Sanjaya. W, 2012. Media Komunikasi Pembelajaran. Edisi Pertama 2012. Jakarta: Kencana Prenamedia Group.

[18]Septanto Henri, 2015. Elearning Menggunakan Edmodo Sebuah Aplikasi Pembelajaran Berbasis Web pada Kelas Shift di STMIK Bina Insani. Bina Insani ICT Journal: Volume 02 Nomor 02.

[19]Setiawan Risky, 2016. Penelitian Tindakan Kelas (Action Research). Semarang: Nuha Medika.

[20]Silberman Mel, 2010. 101 Cara Pelatihan dan Pembelajaran Aktif. Jakarta: PT. Indeks.

[21] Sudjana, 2002. Metoda Statistika. Edisi Keenam 2002. Bandung: Tarsito. [22] Sudijono Anas, 2013. Pengantar Evaluasi Pendidikan. Jakarta: PT. Raja Grafindo Persada.

[23] Sugiyono, 2015. Metode Penelitian Pendidikan. Bandung: Alfabeta.

[24]Sundayana Rostina, 2014. Statistika Penelitian Pendidikan. Bandung: Alfabeta.

[25] Sutopo H.A, 2012. Teknologi Informasi dan Komunikasi dalam Pendidikan. Edisi Pertama 2012. Yogyakarta: Graha Ilmu.

[26]Tulolli, Nani dkk, 2003. Dialog Budaya Wahana Pelestarian dan Pengembangan Kebudayaan Bangsa. Jakarta: CV. Mitra Sari.

[27]Uno B. Hamzah, 2017. Model Pembelajaran Menciptakan Proses Belajar Mengajar yang Kreatif dan Efektif. Jakarta: Bumi Aksara.

[28]Wasis D. Dwiyogo. 2014. Analisi Kebutuhan Pengembangan Model Rancangan Pembelajaran Berbasis Blended Learning (PBBL) untuk Meningkatkan Hasil Belajar Pemecahan Masalah. Jurnal Pendidikan dan Pembelajaran, Vol. 21, No.1, April 2014.

[29]Wulandari A, Puspadewi R.K, 2016. Budaya dan Implikasinya Terhadap Pembelajaran Matematika yang Kreatif. Jurnal Santiaji Pendidikan: Volume 06 Nomor 01. 